\title{
Que inter-relações entre géneros de texto e conhecimento gramatical podem ser objeto de conhecimento explícito e de avaliação?
}

\author{
Antónia Coutinho \\ NOVA FCSH, CLUNL - Universidade NOVA de Lisboa
}

\begin{abstract}
:
In this paper, we discuss epistemological and theoretical approaches of grammatical and textual contents, focusing on their relevance in learning (Portuguese) contexts. We will argue that different epistemological approaches can be used complementarily; however, clear objectives must lead to different assessment tasks, ensuring that they are not masking or merging the specific identity of texts, which can't be reduced to linguistic objects, if we consider them in a social interactionism epistemological approach.
\end{abstract}

Keywords: text; text genre; text type; explicit knowledge; social interactionism

Palavras-chave: texto; género de texto; tipo de texto; conhecimento explícito; interacionismo social

\section{Introdução}

Nesta contribuição propomo-nos refletir sobre as relações entre conhecimentos gramaticais e conhecimentos textuais, numa perspetiva de ensino-aprendizagem - e, de forma particular, de avaliação. Começaremos por destacar dois pressupostos que, decorrendo de análise de práticas comuns, permitirão evidenciar os contornos do problema em análise. Na secção seguinte, focalizaremos o quadro epistemológico do interacionismo social, assumindo o caráter consensual de que se reveste, em termos gerais, no âmbito dos estudos linguísticos sobre os textos e os discursos. Nessa base, equacionaremos os limites e desafios que se colocam, no confronto com trabalhos epistemologicamente diferenciados para, finalmente, analisarmos algumas das inter-relações possíveis entre conhecimentos (explícitos) sobre textos e sobre gramática.

\section{Pressupostos}

A presente contribuição assenta num conjunto de pressupostos que importa explicitar. Em primeiro lugar, assume-se a possibilidade de convivência pacífica e, sobretudo, produtiva, no âmbito do trabalho de didatização, entre conhecimentos teóricos produzidos e estabilizados em quadros teóricos e epistemológicos diferenciados. Referimo-nos concretamente, por um lado, à perspetiva generativista que, em Portugal, enquadra ainda, talvez de forma determinante, os estudos gramaticais; e, por outro, a epistemologias não generativistas que, em termos gerais, poderemos dizer centradas sobre o funcionamento da linguagem, como é o caso da Teoria Formal Enunciativa e das diferentes abordagens adotadas no âmbito de estudos linguísticos sobre os textos e os discursos. Neste último âmbito, inscreve-se a epistemologia interacionista social que sustenta o quadro teórico e epistemológico do Interacionismo Sociodiscursivo em que se situa o presente trabalho. Em síntese, diremos que adotar este último quadro - que assume a natureza inequivocamente social e individual da linguagem - não nos impedirá de recorrer a descrições gramaticais produzidas num quadro de sintaxe generativa, por exemplo. Ou, dito ao contrário: recorrer a descrições gramaticais produzidas num quadro de sintaxe generativa, por exemplo, não nos obriga a partilhar a perspetiva biologizante que, nesse contexto, se atribui ao fenómeno da linguagem.

O segundo pressuposto é, simultaneamente, mais local e mais operacional: decorre da constatação de uma convivência insuficientemente explicitada (por vezes anárquica) entre conceções (linguísticas) de texto (como tipos de texto ou géneros de texto, entre outras), que circulam e são utilizadas em documentos de referência 
para o trabalho docente. Veja-se, por exemplo, a prova de exame de $3 .^{\circ}$ ciclo. $-2014,2 .^{a}$ fase (http://iave.pt/images/arquivo_de_provas/9_ano/91/PF-Port91-Ch2-2014.pdf):

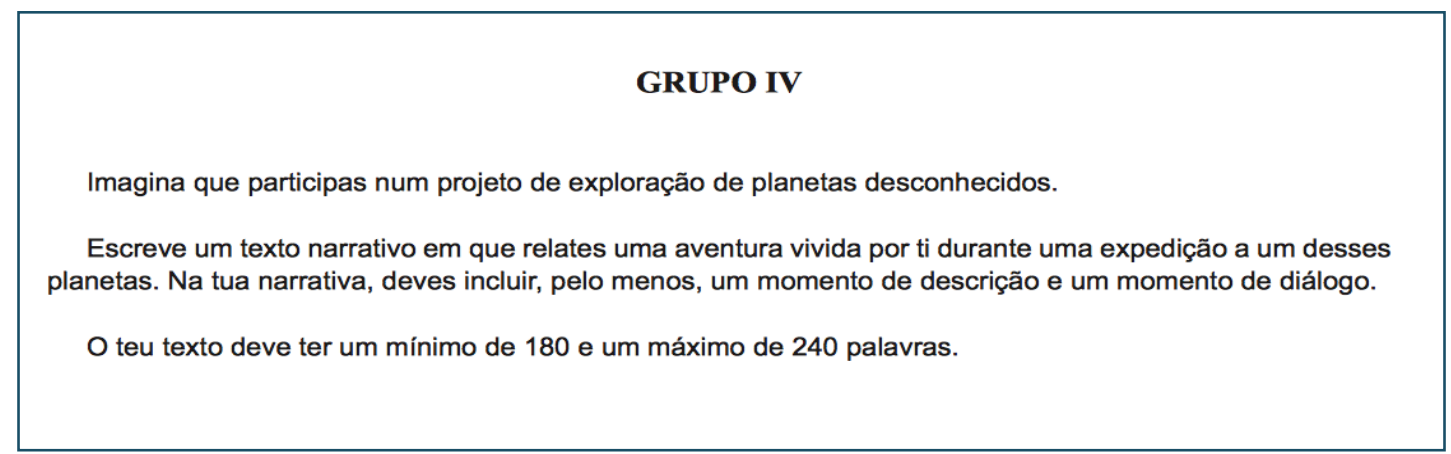

Figura 1: prova de exame de Português de final do $3 .^{\circ}$ ciclo do ensino básico

A ambiguidade da instrução passa, em primeiro lugar, pelo recurso simultâneo a "texto narrativo" e a "narrativa" - mas admitimos que isso não seja particularmente relevante para o ciclo de escolaridade em causa. Já a obrigatoriedade de o texto a ser produzido "incluir, pelo menos, um momento de descrição e um momento de diálogo" parece problemática: o que se toma aqui, afinal, como característico (ou prototípico) do texto narrativo? A presença de descrição e de diálogo? Ou a especificidade macroestrutural do tipo textual narrativo, a implicar uma sucessão de acontecimentos, hierarquizada (e não apenas cronologicamente sequencializada), de acordo com a estrutura (mínima) que corresponde a situação inicial, complicação e resolução? A consulta dos critérios de correção, igualmente disponibilizados no Arquivo do IAVE (cf. http://iave.pt/images/arquivo_de provas/9 ano/91/PF-Port91-Ch2-2014-CC.pdf), mostra que o segundo aspeto é tido em conta mas a ambiguidade permanece na correção:

\begin{tabular}{|c|c|c|c|c|c|c|}
\hline \multirow{2}{*}{\multicolumn{2}{|c|}{ PARARTAÇÃOO }} & \multicolumn{5}{|c|}{ DESCRIÇÃO DOS NÍVEIS DE DESEMPENHO } \\
\hline & & 5 & 4 & 3 & 2 & 1 \\
\hline 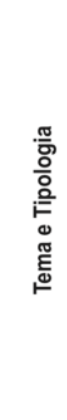 & A & $\begin{array}{l}\text { Cumpre integralmente a } \\
\text { instrução quanto a: } \\
\text { - tema (escreve um texto sobre } \\
\text { uma aventura vivida durante } \\
\text { uma expedição a um planeta } \\
\text { desconhecido) } \\
\text { E tipo de texto - texto narrativo } \\
\text { com, pelo menos, uma sequência } \\
\text { descritiva e um momento de } \\
\text { diálogo. } \\
\text { O texto deve incluir: } \\
\text { - abertura que contextualize } \\
\text { a situação inicial; } \\
\text { - desenvolvimento e } \\
\text { desfecho adequados. }\end{array}$ & $\begin{array}{l}\mathbf{N} \\
\mathbf{i}\end{array}$ & $\begin{array}{l}\text { Cumpre parcialmente a } \\
\text { instrução quanto a: } \\
\text { - tema (texto com alguns desvios } \\
\text { temáticos) } \\
\text { tipo de texto (texto de tipo } \\
\text { hibrido, mas predominantemente } \\
\text { narrativo). }\end{array}$ & $\begin{array}{l}\text { N } \\
\text { í } \\
\text { V }\end{array}$ & $\begin{array}{l}\text { Segue a instrução de forma } \\
\text { insuficiente quanto a: } \\
\text { - tema (texto tratando o tema } \\
\text { dado de forma muito vaga ou } \\
\text { tratando-o num plano secundário) } \\
\text { tipo de texto (texto híbrido, sem } \\
\text { predomínio das características } \\
\text { do texto narrativo). } \\
\text { oU } \\
\text { Cumpre apenas uma das } \\
\text { instruçōes (tema ou tipo de texto). }\end{array}$ \\
\hline
\end{tabular}

Figura 2: critérios de correção da prova de exame de Português de final do $3 .^{\circ}$ ciclo do ensino básico 
Com efeito, para o mais alto nível de desempenho, no que diz respeito ao parâmetro (ou subparâmetro) tipologia, há um desdobramento de descritores que contempla os dois aspetos referidos: por um lado, a inclusão de descrição e de diálogo, explicitada na instrução; por outro, a organização macroestrutural característica do tipo narrativo. Mas os outros dois níveis de desempenho, que admitem a possibilidade de um "texto de tipo híbrido", não explicitam quais as características que devem (ou deveriam) ser consideradas como "características do texto narrativo". Esta indefinição, se assim se pode dizer, pode explicar, pelo menos em parte, uma das conclusões do Relatório do IAVE relativamente às provas finais do 9. ${ }^{\circ}$ ano, em 2014:

(...) quando foi solicitado um texto narrativo, os resultados foram melhores (a classificação média em relação à cotação foi $71 \%$, na prova de 2011), eventualmente por esta tipologia textual ter uma estrutura menos rígida que a de um texto de opinião; (...) (IAVE, 2015).

Está longe de ser evidente o facto de um texto de caráter narrativo (como são, geralmente, uma história ou um conto, por exemplo) ter uma estrutura menos rígida do que a de um texto de opinião. Se considerarmos os aspetos referidos na instrução do exemplo anteriormente analisado, poderemos dizer que nada obsta a que um texto de opinião integre também "um momento de descrição e um momento de diálogo". Já será uma questão diferente saber se esses hipotéticos momentos (de descrição e de diálogo) fazem parte do que se possa considerar a estrutura mais frequente ou mais previsível de um texto de opinião. A resposta será negativa. Mas poderse-á dizer que a descrição e o diálogo fazem parte da estrutura mais frequente ou mais previsível de um texto de caráter narrativo? A resposta será igualmente negativa. A explicação para isto tem a ver com o facto de se confundir géneros de texto (como o romance ou o conto, por exemplo) com o modo narrativo que geralmente é usado em textos desses géneros, por um lado, e com o caráter sequencial prototípico, que pode estar associado ao modo narrativo, por outro. Assim, a descrição e o diálogo são elementos frequentes e, como tal, previsíveis, na construção de textos do género romance ou conto. Mas o modo narrativo que provavelmente os caracteriza define-se através dos tempos gramaticais em ocorrência, que localizam os acontecimentos representados relativamente a um ponto de referência temporal; e uma sequência narrativa prototípica (ou, como frequentemente se diz, um tipo de texto narrativo) acontece quando o modo narrativo organiza sequencialmente a ação em fases, a incluir, pelo menos, uma situação inicial, uma complicação e uma resolução. Se pensarmos, por exemplo, no Livro de Linhagens do Conde D. Pedro (Brocardo, 2006) facilmente se identifica o modo narrativo associado aos blocos linhagísticos que constituem a maior parte do texto, e de que aqui se reproduz um exemplo (escolhido de forma praticamente aleatória): 
De dona Tereia martijz fillha de Martí xira e de dona Tereia anes filha de dô iohã fernãdez de riba d'auizela e de dona Maria soarez filha de dô soeiro meendez o gordo.

Esta dona Tereía anes foy casada có dó paay ueegas d'aluarēga filho de dó egas afonso. que foy neto de moço ueegas e fez ẽ ela pero paaez curuo. e Louréço paaez d'aluarêga. e dona sancha paaez que foy casada có dõ fernã gomez bareto. ${ }^{171}$

Este pero paaez curuo foy casado có dona guyomar afonso gata filha de dó afonso perez gato. E fez ẽ ela Martĩ perez que chamarô d'aluarēga. E dona steuaynha perez que foy casada có meẽ rodriguyz rebotĩ. E ouueró huum filho que ouue nome $\mathrm{Martī} \mathrm{meẽdez}{ }^{172}$ rebotim que moreo sem semel. E Martĩ perez foy casado cõ dona ynes paaez filha de paay rodriguyz de ualadares que chamarô paay souela. $e$ de dona aldốça rodriguyz de telha. $e$ fez é ela huũ filho que ouue nome pero paaez. e outro filho que ouue nome afonso martijz que era o melhor deles. e outro que ouue nome nuno martijz. E afonso Martijz $e$ nu/(b)no martijz moreró sem semel. E outra freyra que ouue nome dona ynes martijz. e outra filha que ouue nome dona aldoça martijz. E esta dona aldóça martij̄z foy casada cô Martĩ meēdez de uascócelos. e ouueró semel. E pero paaez suso dito foy casado cô dona iohãna rodriguiz fitha de roy martiǰ̨ de nomãaes e ouuerō geeraçõ ${ }^{173}$

De Lourêço paaez d'aluarẽga filho de paay ueegas

Este Lourêço paaez d'aluaréga foi casado có dona mafalda perez filha de dó pero fernãdez de portogal. e de dona froylhi rodriguyz de pereira. e fez ẽ ela hũa filha que foy freira d'arouca.

Figura 3

Como mostra este exemplo, os segmentos linhagísticos são construídos no modo narrativo, com ocorrência reiterada de formas verbais no pretérito perfeito simples (“...foi casado(a) cõ...”, “... fez e ela ...", “...ouue nome...", entre outras); mas não há sequencialização narrativa prototípica, uma vez que se verifica apenas uma enumeração de ações ou acontecimentos, que se sucedem sem outra forma de organização sequencial. Pelo contrário, o chamado episódio da Batalha do Salado, que ocorre também no interior do Livro de Linhagens (título XXI), apresenta uma estrutura narrativa prototípica:

- situação inicial, com a batalha, "muy doorida de crueza e de sanha", a ser dominada pelo exército oposto;

- nó desencadeador ("Estãdo os cristaaos ẽ esta presa e coita e auẽtuira sem esperança Chegarõ tres caualeiros ao priol dõ aluaro de pereira e disserõlhi. Senhor que fazedes os cristaãos estã ẽ perdiçõ asi como ueedes si deus hi nõ põ outra sauaçõ (...)";

- desenlace (resolução) (“(...) olharõ por ela e uirõna [a uera cruz] andar antre os mouros. e logo en si sentirõ que a graça de deus era cõ eles porque se acharõ aquela ora ualẽtes e esforçados come ẽ começo da lide. (...)";

- situação final, seguida de avaliação, ou moral (“Os mouros uirõ que seu feito ya pera mal de todo. diserõ que seu mafomede nõ auia poder pera os defender. Ali começarõ de fugir e gram parte deles pera a az do coral 
que estaua cõtra a ribeira do mar que ainda estaua folgada. Aqui se cõpriu o que disse o priol dõ aluaro de pereira a el Rei dõ afomso que el pela sãta uera cruz e pelos nobres fidalgos auia de uẽçer primeiro.”).

Compreender-se-á talvez melhor, agora, a confusão que pode gerar a passagem atrás citada, que aqui se reproduz parcialmente: "eventualmente por esta tipologia textual [texto narrativo] ter uma estrutura menos rígida que a de um texto de opinião; (...)". A primeira dificuldade decorre do facto de se tratar o "texto narrativo" como uma tipologia textual: ora o texto de tipo narrativo, ou o texto narrativo prototípico, não é uma tipologia mas sim um dos cinco casos da tipologia textual (sequencial) geralmente considerada na bibliografia, de acordo com Adam (2011), que inclui, a par do tipo narrativo, os tipos descritivo, argumentativo, explicativo e dialogal; também o texto de opinião não é uma tipologia mas sim um género cujos exemplares recorrem, com frequência, à estruturação sequencial prototípica argumentativa (ou ao tipo argumentativo, se se preferir).

Como é evidente, a análise destes casos não põe de forma nenhuma em causa a seriedade do trabalho e do contexto a que estão associados: trata-se apenas de evidenciar algumas ambiguidades ou oscilações (conceptuais e terminológicas) que podem ter um impacto significativo, tanto no desempenho de quem é estudante como no trabalho de quem é docente. Os exemplos em causa são datados e servem aqui, sobretudo, como suporte para a reflexão. Convirá, por isso mesmo, sublinhar as propostas recentes de correção de perguntas de escrita, globalmente coerentes e teoricamente bem articuladas. No que diz respeito ao problema em análise, sublinhase também o papel desempenhado pelas Aprendizagens Essenciais (DGE-MEC, 2018), que vieram contribuir de forma positiva para a redução de ambiguidades e contradições. Mas o problema persiste. Um exemplo simples pode ser o do Dicionário Terminológico (Costa \& Aguiar e Silva, 2008) que, na entrada Plano de texto, parece sugerir um valor sinonímico para as expressões tipo e género, embora os exemplos correspondam apenas, e de forma inequívoca, a géneros de texto: “(...) Todo o texto se integra num tipo ou num género textuais - relatório, crónica, notícia, artigo científico, discurso político, conto, poema épico, tragédia, etc. - (...)” (Costa \& Aguiar e Silva, 2008).

\section{A epistemologia interacionista social}

O quadro teórico e epistemológico do Interacionismo Sociodiscursivo (ISD) (Bronckart, 1997) assume-se na continuidade da corrente de pensamento conhecida como interacionismo social, partilhada por diferentes autores do início do século XX, com destaque para o papel fundador de Vigotsky e Voloshinov. O programa de trabalho do ISD focaliza o papel central da linguagem no desenvolvimento da pessoa, nas fases precoces de desenvolvimento da linguagem, na infância, mas também ao longo da vida. Trata-se, assim, de compreender as relações entre ação, pensamento e linguagem - esta última a compreender, e a estudar, como texto/discurso que mobiliza os recursos gramaticais de uma dada língua em uso. No presente contexto, mais do que desenvolver pormenorizadamente a especificidade do ISD, importará clarificar a epistemologia de base que o sustenta e que, radicando em autores fundadores como Vigotsky e Voloshinov, assume o primado do social. Isto significa, por um lado, que o social é determinante da própria constituição das identidades individuais, como evidencia Vigotsky:

Nous nous connaissons nous-mêmes parce que nous connaissons les autres, et par le même procédé que celui par lequel nous connaissons les autres, parce que nous sommes par rapport à nousmêmes les mêmes que les autres par rapport à nous. (...) la conscience est en quelque sorte un contact social avec soi-même. (Vigotsky, [1925]1994, pp. 47-48)

Esta perspetiva converge com a forma como Voloshinov privilegia a dimensão interacional da enunciação (em detrimento do ato individual de produção): 
La véritable substance de la langue n'est pas constituée par un système abstrait de formes linguistiques ni par l'énonciation-monologue isolée, ni par l'acte psycho-physiologique de la production, mais par le phénomène social de l'interaction verbale, réalisée à travers l'énonciation et les énonciations. L'interaction verbale constitue ainsi la réalité fondamentale de la langue. (Voloshinov [1929]1977, pp.135-136).

Ainda que muito brevemente referidos, os aspetos apontados permitem compreender a opção metodológica descendente para o estudo da língua que Voloshinov ([1929]1977, p. 137) claramente preconiza: em primeiro lugar, o estudo das condições em que se realizam as interações verbais; a seguir, as diferentes possibilidades que pode assumir a interação verbal; finalmente, as formas da língua. Por outras palavras: do(s) contexto(s) ao(s) texto(s), ou ao(s) género(s) de texto, e deste(s) às estruturas linguísticas, ou gramaticais em ocorrência ${ }^{1}$. Esta abordagem descendente, que decorre, como acabamos de ver, do primado (epistemológico) do social, pode considerar-se consensual no âmbito dos estudos linguísticos sobre os textos e os discursos opondo-se, pelo contrário, à conceção biologizante e inata da linguagem, para a qual a questão textual seria secundária relativamente à estruturação do sistema da língua. Apesar desta oposição, parece viável pensar que, de um ponto de vista didático, se podem revelar úteis e produtivas opções metodológicas variadas e alternadas, ou simplesmente percursos diferenciados: dos contextos e dos textos às estruturas gramaticais, mas também das estruturas gramaticais aos textos e aos respetivos contextos. Esta solução de compromisso, também apontada por Bronckart (1997, p. 91), reitera o pressuposto atrás assumido - mas exige que se perspetivem com clareza as possibilidades da convivência epistemológica, como veremos no ponto seguinte.

\section{Limites e desafios da convivência epistemológica}

Como atrás ficou dito, parece compatível, a quem trabalha no quadro da epistemologia interacionista social, recorrer a descrições de estruturas gramaticais desenvolvidas no âmbito da gramática generativa. Pelo contrário, a recondução do objeto texto a um objeto gramatical aparece como uma cedência impossível - simplesmente porque, como atrás se viu, os conhecimentos sobre texto(s) e género(s) de texto não são conhecimentos gramaticais.

É essa, no entanto, a conceção assumida pela Gramática da Língua Portuguesa no capítulo 3D, intitulado Sintaxe e Semântica -frase simples e frase complexa (Raposo et al., 2013, pp. 1691-1755). Com efeito, é neste âmbito que são descritas questões de ordem textual: a primeira secção desse capítulo, a secção 34, intitula-se Organização textual e articulação de orações (Mendes, 2013, pp. 1691-1746) seguindo-se-lhe a secção 34A, intitulada Tipologias textuais (Nascimento, 2013, pp. 1747-1755). Uma tal organização só pode ser entendida na lógica de uma conceção estritamente linguística de texto (apesar de serem referidos os parâmetros da textualidade, apresentados em Beaugrande, 1980 e Beaugrande \& Dressler, 1981). Ao contrário deste posicionamento - que subordina o texto à frase composta e à frase complexa, ou às estruturas de coordenação e de subordinação, o Dicionário Terminológico (DT) preserva a especificidade de um conjunto de disciplinas (Análise de Discurso, Retórica, Pragmática e Linguística Textual) que, genericamente, se podem aqui considerar no âmbito de uma linguística do uso (cf. Fonseca, 1994), distinta das disciplinas de ordem gramatical, reunidas sob a designação geral de Linguística Descritiva. É o que mostra a estrutura hierárquica do DT e da secção dedicada a texto:

\footnotetext{
${ }^{1}$ Nas palavras de Voloshinov, [1929]1977: 137: “(...) des formes de la langue dans leur interprétation linguistique habituelle."
} 


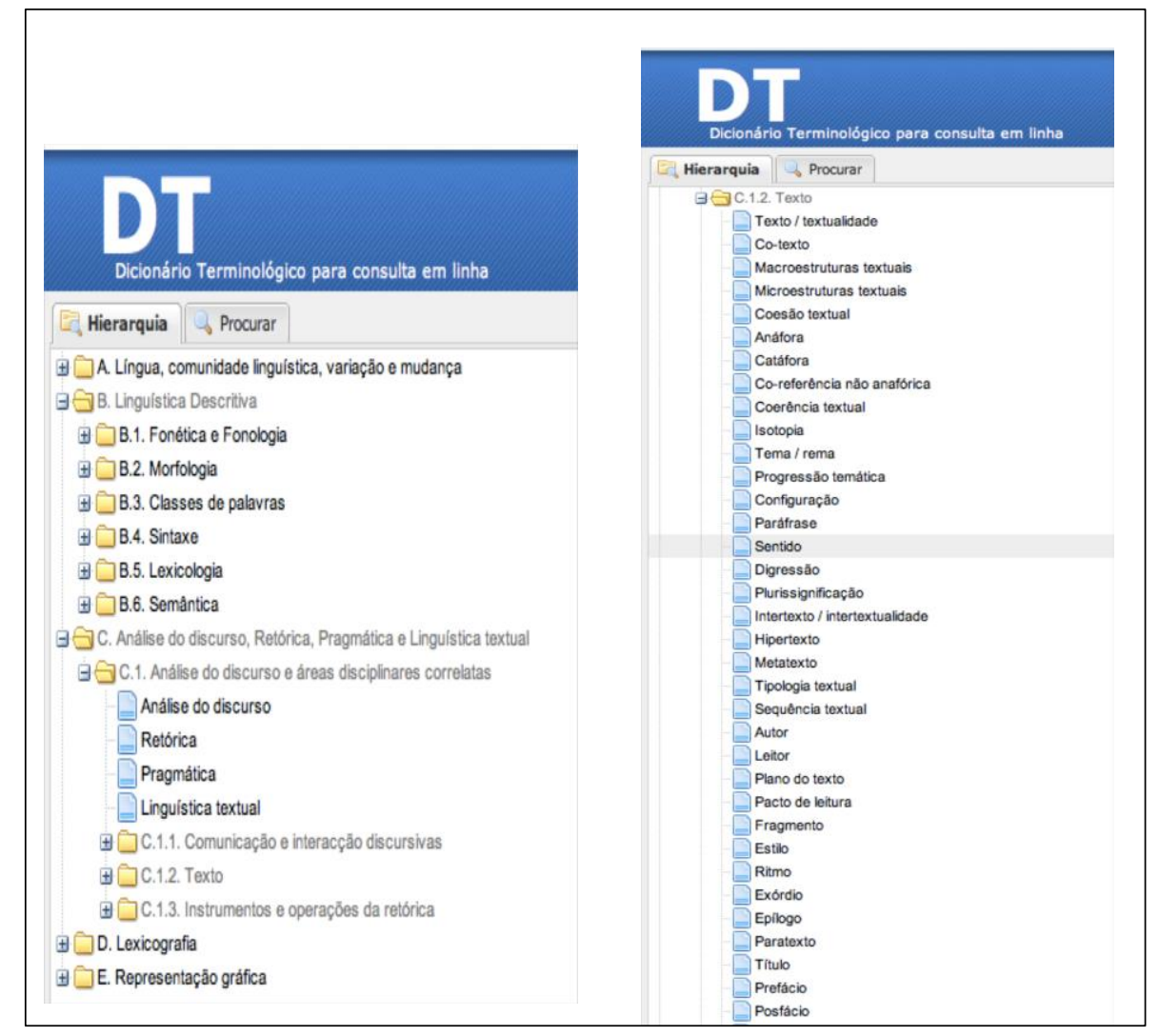

Figura 4: estrutura do Dicionário Terminológico

Inversamente, importa sublinhar que os conhecimentos sobre texto(s) e género(s) de texto não devem (ou não podem) dispensar o recurso a conhecimentos gramaticais.

Que inter-relações se podem, então, estabelecer, numa perspetiva de ensino-aprendizagem e, de forma mais específica, em termos de avaliação?

\section{Inter-relações}

São inter-relações habituais as que focalizam aspetos gramaticais como suporte para o trabalho de leitura/compreensão de textos. Veja-se, a título de exemplo, a instrução que se segue: 
2. Seleciona a opção que corresponde à única afirmação falsa, de acordo com o sentido do texto.

Escreve o número do item e a letra que identifica a opção escolhida.
(A) «que» (linha 16) refere-se a «um John Ninguém».
(B) «que» (linha 19) refere-se a «o planeta».
(C) «que» (linha 23) refere-se a «uma obra».
(D) «que» (linha 34) refere-se a «um patrocinador bilionário».

Figura 5: prova de exame de final de $3 .^{\circ}$ ciclo, 2013, 2. ${ }^{a}$ fase

Neste tipo de abordagem - cuja utilidade e pertinência não pomos em causa - encara-se o conhecimento gramatical (e respetiva avaliação) do ponto de vista do contributo que pode dar para a compreensão do sentido. Em última análise, ou de forma mais geral, perspetivam-se os conhecimentos gramaticais como elementos facilitadores dos processos de compreensão e de produção textuais:

Mais directamente dependente do ensino explícito, formal e sistematizado e sendo transversal a estas competências [compreensão do oral, expressão oral, leitura e escrita], o conhecimento explícito da língua permite o controlo das regras e a selecção dos procedimentos mais adequados à compreensão e à expressão, em cada situação comunicativa. (Reis et al., 2009, pp. 15-16)

Ainda que, como acima dissemos, reconheçamos a pertinência deste tipo de trabalho, admitimos que não seja suficiente: ele dilui, ou apaga, a dimensão propriamente textual do objeto em análise, atomizando o sentido, ou reduzindo-o ao funcionamento da estrutura gramatical em análise. Consideramos assim que aprender / ensinar o conhecimento explícito da língua é necessário mas não suficiente: é necessário também aprender/ensinar o conhecimento explícito dos textos (de textos de diferentes géneros, literários e não literários).

Sem querermos repetir o que atrás ficou exposto, não podemos deixar de sublinhar que o conhecimento explícito do(s) (géneros de) texto(s) implica aspetos contextuais e organizacionais (macroestruturais e microestruturais). Ainda que, como em todo o trabalho de investigação ou de análise, seja legítimo e certamente necessário fazer recortes (metodológicos), não pode deixar de se destacar o interesse de abordagens complementares, suscetíveis de darem conta da complexidade inerente aos objetos textuais. Nesta perspetiva, que lugar pode caber ao ensino-aprendizagem, e à avaliação, de conhecimento gramatical?

Uma das inter-relações desejáveis, deste ponto de vista, tem a ver com trabalho (explícito) sobre formas ou estruturas linguísticas específicas que constituem um aspeto decisivo para o (re)conhecimento/domínio do (género de) texto em análise ou em produção. Este trabalho pode passar pela identificação (observação, reconhecimento, sistematização e reutilização) de estruturas gramaticais características de determinado género (cf, Dolz, Noverraz \& Schneuwly, 2004, p.115). Mas pode também desenvolver-se diferencialmente, identificando o recurso às mesmas estruturas gramaticais em diferentes géneros de texto ou, pelo contrário, $\mathrm{o}$ recurso a diferentes estruturas gramaticais em exemplares de um mesmo género de texto. é este último caso que podem ilustrar os dois textos que a seguir se reproduzem, retirados da revista $U p$ (fevereiro de 2015): 

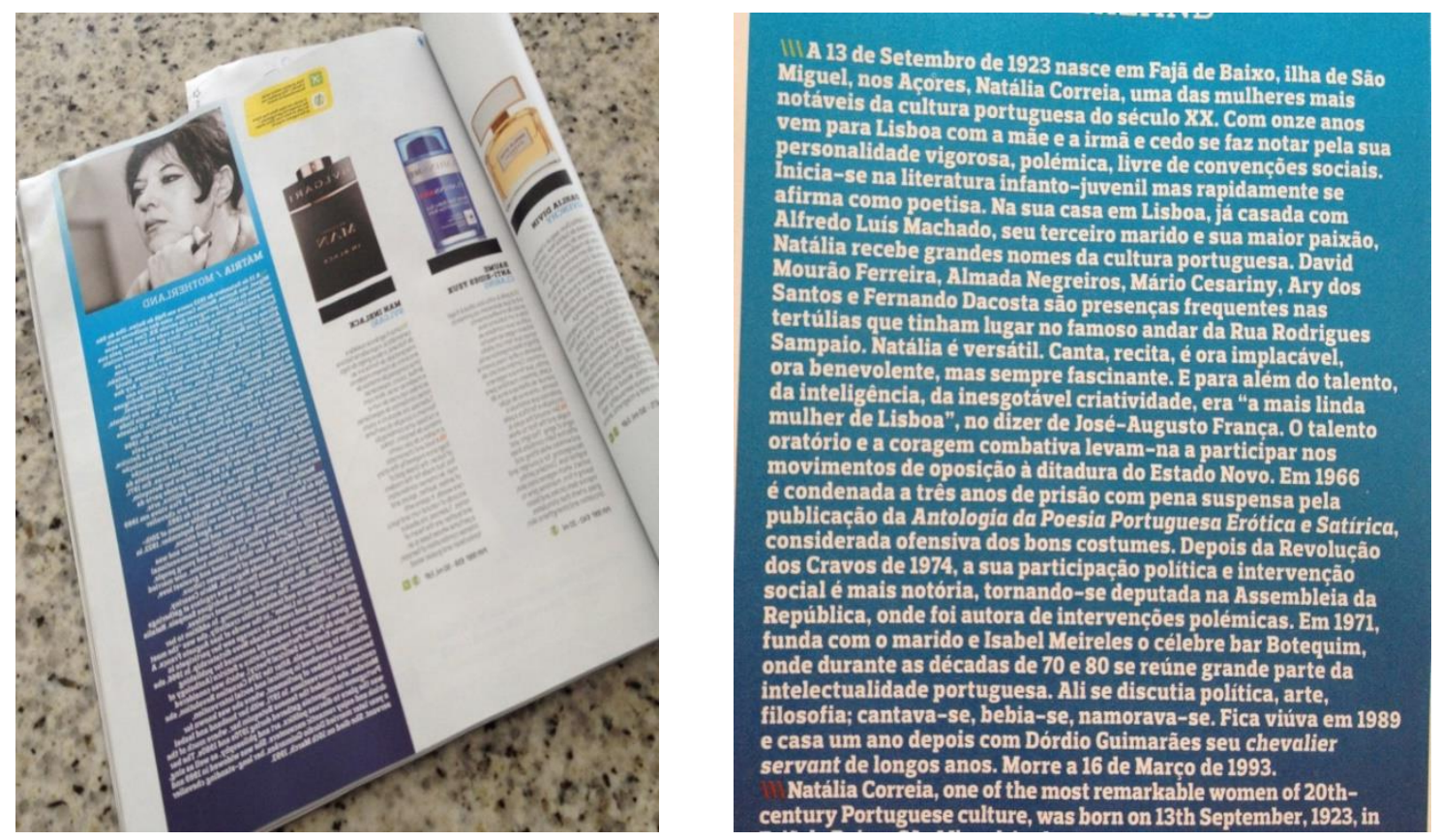

Figura 6: nota biográfica de Natália Correia
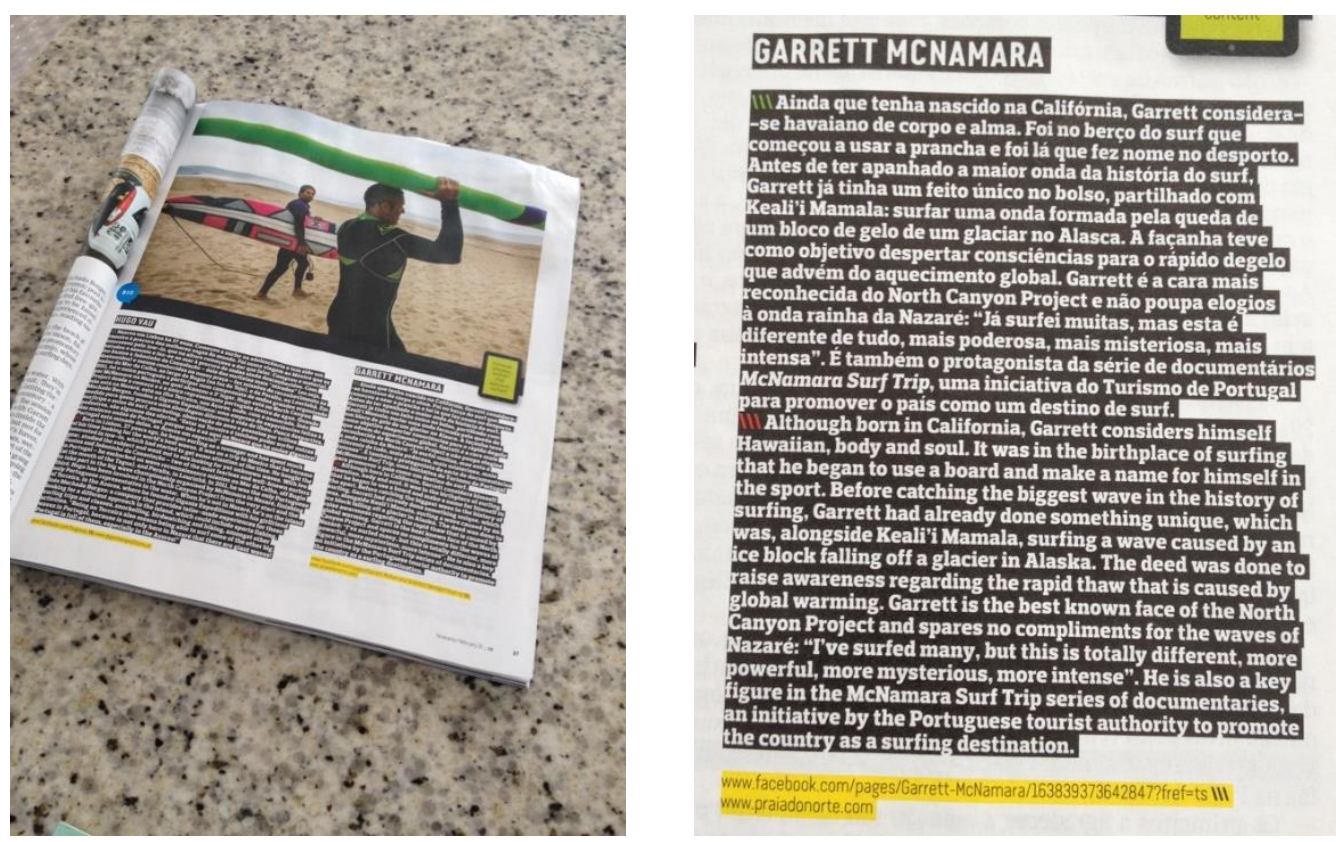

Figura 7: nota biográfica de Garrett MacNamara 
Trata-se de duas notas biográficas, publicadas no mesmo número da revista $U p$, em fevereiro de 2015. Uma primeira leitura evidencia recursos gramaticais diferentes: na nota biográfica de Macnamara, constata-se a oposição entre o desenvolvimento, com formas verbais no pretérito perfeito simples, a configurarem a enumeração de momentos/episódios da (história de) vida, e a conclusão, em que ocorrem formas verbais no presente do indicativo com valor deítico e estrutura de definição (X é Y); a nota biográfica de Natália Correia, pelo contrário, está cronologicamente estruturada, verificando-se, no entanto, a ocorrência de presente do indicativo sem valor deítico. Que valores se associam ao uso destes diferentes tempos gramaticais? Haverá algum aspeto contextual que determine esses usos? A observação orientada e a sistematização destes usos permitem a sua reutilização em situação de produção?

\section{Conclusão}

A concluir, limitar-nos-emos a reiterar, evocando agora também Coseriu (2007), que os textos não podem ser considerados como "meros factos de língua" (Coseriu, 2007: 139). Mas esses mesmos textos - na complexidade que os caracteriza - não podem ser trabalhados (compreendidos, produzidos) sem os recursos linguísticos que mobilizam. Diz Bernardo Soares (1982: 21), em O Livro do Desassossego:

Analysando-me á tarde, descubro que o meu systema de estylo assenta em dois principios, e immediatamente, e á boa maneira dos bons classicos, erijo esses dois principios em fundamentos geraes de todo estylo: dizer o que se sente exactamente como se sente - claramente, se é claro; obscuramente, se é obscuro; confusamente, se é confuso -; comprehender que a grammatica é um instrumento, e não uma lei.

Não se creia que isto é “apenas" uma questão de estilo. A gramática pode (e provavelmente deve) ser estudada e avaliada em si mesma. Mas quando o objeto de análise é o texto, o que importa saber (compreender, saber fazer) e avaliar é o que cada estudante ou cada pessoa é capaz de fazer com os instrumentos gramaticais de que dispõe.

\section{Referências}

Adam, J.-M. (2011) Les textes : types et prototypes. Paris: Armand Colin.

Beaugrande, R. (1980) Text, Discourse and Process. Toward a multidisciplinary science of texts. London: Longman.

Beaugrande, R. \& Dressler, W. (1981) Introduction to textlinguistics, London: Longman.

Brocardo, T. (2006). Livro de Linhagens do Conde D. Pedro. Edição do fragmento manuscrito da Biblioteca da Ajuda (século XIV). Lisboa: Imprensa Nacional - Casa da Moeda.

Bronckart, J.-P. (1997) Activité langagière, textes et discours. Pour un interactionisme socio-discursif. Lausanne: Delachaux et Niestlé.

Coseriu, E. (2007) Linguística del texto. Introducción a la hermenêutica del sentido. Madrid: Arco/Libros, S.L.

Coutinho, M. A \& Correia, C. N. (2013) Uma leitura de 'Homero'. In J. Markic \& C. N. Correia (eds), Descrições e contrastes. Tópicos de gramática portuguesa com exemplos contrastivos eslovenos (pp. 121 136). Ljubliana: Univerza v Ljubljani.

Coutinho, M. A.; Tanto, C.; Luís, R. (2015) O conhecimento explícito dos textos e da língua. In E. Leurquin, A. Coutinho \& F. Miranda, Formação docente. Textos, teorias e práticas (pp. 133 - 164). Campinas, SP: Mercado de Letras.

Dolz, J. \& Schneuwly, B. (2004) Géneros orais e escritos na Escola. Campinas: Mercado de Letras. 
Dolz, J., Noverraz, N. \& Schneuwly, B. (2004) Sequências didáticas para o oral e a escrita: apresentação de um procedimento. In R. Rojo \& G. Cordeiro (Org. e trad.), Géneros orais e escritos na escola (pp. 95-128). Campinas: Mercado de Letras.

Fonseca, J. (1994) O lugar da pragmática na teoria e na análise linguísticas. Em J. Fonseca, Pragmática linguística. Introdução, teoria e descrição do português (pp. 301-314). Porto: Porto Editora.

Mendes, A. (2013) Organização textual e articulação de orações. In E. P. Raposo, Gramática do Português (pp. 1691 - 1746). Lisboa: FCG.

Nascimento, M. F. B. (2013) Tipologias textuais. In E. P. Raposo, Gramática do Português (pp. 1747 - 1755 ). Lisboa: FCG.

Raposo, E. P. et al. (2013) Gramática do Português. Lisboa: FCG.

Vygotski, L. ([1925]1994) La conscience comme problème de la psychologie du comportement. Société française, 50, pp. 35-50.

Voloshinov, V. N. ([1929]1977) Le marxisme et la philosophie du langage. Paris: Minuit.

Outras referências

Costa, J. \& Aguiar e Silva, V. M. (orgs.) (2008) Dicionário Terminológico. URL: http://dt.dge.mec.pt.

DGE- MEC (2018) Aprendizagens Essenciais - Português, $9^{\circ}$ Ano, [PDF]. URL: http://www.dge.mec.pt/sites/default/files/Curriculo/Aprendizagens_Essenciais/3_ciclo/portugues 3c 9a ff.pdf

IAVE (2015) Relatório final 2010-2014. Provas Finais $2 .^{\circ} e 3^{\circ}$ Ciclos do Ensino Básico. URL:http://iave.pt/images/FicheirosPDF/Docs_Avaliação_Alunos/Relatórios/Relat_EB_2015_LV.pdf

Reis, C. (coord) (2009) Programas de Português do Ensino Básico. Lisboa: ME-DGIDC.

Soares, B. (1982) Livro do Desassossego. Lisboa, Ática. 